\title{
Survey of Alimentary Radiology Findings in the North-east of Scotland Region (1967-70)
}

\author{
J. C. PETRIE， C. D. NEEDHAM， L. A. GILLANDERS
}

British Medical fournal, 1972, 2, 78-80

\section{Summary}

This report describes a survey of all barium contrast radiological examinations carried out in the years 196770 by the unit that serves $99 \%$ of the adult population of North-east Scotland. The survey method used yields useful estimates, not otherwise available, of the occurrence of some forms of alimentary lesions within a whole community. Rates of occurrence by age and sex were recorded for all lesions. The data on peptic ulceration, were compared with those from South-east and from North England, and this showed that duodenal, but not gastric, ulceration is much commoner in North-east Scotland. Occurrence rates for most lesions have been nearly unchanged throughout the four years of survey. The data provide a measure of the work load for these radiological examinations for a given population.

\section{Introduction}

This survey was designed to derive estimates of the rates of occurrence of lesions of the alimentary tract detected by radiology in all patients referred from a large, defined, geographical region. A second aim was to obtain an index of successive cohorts of patients as a basis for detailed studies of specific lesions. A further incidental aim was to establish the work load on a radiology service for a given population.

This report presents a selection of the findings for the first four years of the survey.

\section{Materials and Methods}

Ninety-nine per cent. of alimentary radiological examinations for the population over 12 years of age in North-east Scotland and Shetland (172,028 males, 196,902 females) are provided by the Department of Radiology in the Aberdeen Teaching Hospital Group. The remaining examinations, which are not included in this survey, are performed in a private nursing home. The consultant staff carry out and supervise all radiological examinations. There is a "direct access" scheme for general practitioners for examinations of the oesophagus, stomach, and duodenum.

The survey is based on agreed standard diagnostic terms. A full copy report of each examination is submitted to the Gastroenterological Research Unit, classified by the same doctors (C.D.N. and J.C.P.), and indexed by the same secretary. The information on each patient is entered on a summary card for each selected diagnostic category. There are no double entries for the same or ensuing years. Lesions which are suspected but not firmly diagnosed by radiology were indexed and are available for follow-up studies, but are not included in the results.

\section{Department of Therapeutics and Clinical Pharmacology, University} of Aberdeen

J. C. PETRIE, M.B., CH.B., M.R.C.P., Senior Lecturer

\section{Aberdeen General Hospitals}

C. D. NEEDHAM, M.D., F.R.C.P., Consultant Physician

L. A. GILLANDERS, M.B., M.R.C.P., F.F.R., Consultant-in-Charge, Department of Diagnostic Radiology
The items recorded are: hospital number, name, age a diagnosis, sex, and details of past and present alimentary contrast radiological examinations. The study was begun on 1 January 1967 , after a pilot period of four months.

\section{Results}

The referral rates for examination per $10^{5}$ of the population over 12 years of age and the percentage of examinations with abnormal findings are shown in Table I. There was little variation throughout the period 1967-70.

TABLE I-Alimentary Contrast Radiology, 1967-70 (29,512 Examinations)

\begin{tabular}{|c|c|c|c|c|c|}
\hline & & \multicolumn{2}{|c|}{$\begin{array}{l}\text { Referral Rate } \\
\text { per } 10^{5} \text { Population } \\
\text { per Annum }\end{array}$} & \multicolumn{2}{|c|}{$\begin{array}{l}\% \text { Abnormal } \\
\text { Findings }\end{array}$} \\
\hline & & M. & F. & M. & F. \\
\hline $\begin{array}{l}\text { Oesophagus, stomach, } \\
\text { and duodenum. } \\
(66 \%) \\
19,667 \text { examinations }\end{array}$ & $\begin{array}{l}1967 \\
1968 \\
1969 \\
1970\end{array}$ & $\begin{array}{l}1,499 \\
1,578 \\
1,463 \\
1,572\end{array}$ & $\begin{array}{l}1,143 \\
1,107 \\
1,087 \\
1,310\end{array}$ & $\begin{array}{l}58 \\
56 \\
56 \\
55\end{array}$ & $\begin{array}{l}51 \\
44 \\
44 \\
47\end{array}$ \\
\hline $\begin{array}{l}\text { Small intestine. } \\
(7 \%) \\
1,935 \text { examinations }\end{array}$ & $\begin{array}{l}1967 \\
1968 \\
1969 \\
1970\end{array}$ & $\begin{array}{l}107 \\
106 \\
109 \\
160\end{array}$ & $\begin{array}{l}119 \\
135 \\
133 \\
174\end{array}$ & $\begin{array}{l}27 \\
21 \\
23 \\
12\end{array}$ & $\begin{array}{r}24 \\
17 \\
16 \\
9\end{array}$ \\
\hline $\begin{array}{l}\text { Colon. } \\
(27 \%) \\
7,910 \text { examinations }\end{array}$ & $\begin{array}{l}1967 \\
1968 \\
1969 \\
1970\end{array}$ & $\begin{array}{l}440 \\
495 \\
500 \\
550\end{array}$ & $\begin{array}{l}520 \\
559 \\
584 \\
620\end{array}$ & $\begin{array}{l}42 \\
47 \\
46 \\
49\end{array}$ & $\begin{array}{l}41 \\
46 \\
48 \\
45\end{array}$ \\
\hline
\end{tabular}

Only an illustrative selection of the information concerning lesions detected by radiology over the four-year period is presented in this first general report. Annual totals and estimates of the rates of detection per $10^{5}$ of the population are shown in Tables II and IV.

\section{OESOPHAGUS, STOMACH, AND DUODENUM}

A selection of the lesions indexed is shown in Table II. In the oesophagus the commonest lesions were reflux and axial hiatal hernia; these did not always coincide. Mixed and paraoesophageal hernias accounted for $4.6 \%$ and $3.3 \%$ respectively of all hiatal hernias found. Oesophageal lesions except for carcinoma and varices showed a female excess.

Gastric ulcers were indexed either as ulcers of body of stomach or of the antrum/prepyloric area. The ratio of duodenal plus pyloric ulcers to all gastric ulcers for males and females was $8 \cdot 6: 1$ and $5 \cdot 1: 1$ respectively. The male : female ratios are also shown. Although details for all lesions indexed are available, for reasons of space only peptic ulcer is used as an illustrative example. The age at diagnosis and the rates of detection per $10^{5}$ of the population are presented in Table III and compared with data from South-east England (Doll, Jones, and Buckatzsch, 1951), and for Northern England (Yorkshire) (Pulvertaft, 1959).

Gastric carcinoma was diagnosed firmly more often than oesophageal carcinoma $(1.6: 1)$, and unlike oesophageal carcinoma showed a slight male excess $(1 \cdot 4: 1)$. Duodenal diverticula, excluding pseudodiverticula of the first part of the duodenum, were very common, but the sex ratio contrasts with that of duodenal ulcer. 


\section{SMALL INTESTINE}

A "malabsorption pattern" was seen in 120 patients (Table IV). The term is morphologically descriptive and does not denote a particular pathological condition. Small-intestinal diverticula, like gastric, colonic, and duodenal diverticula, showed a female excess. Crohn's disease of the small intestine was sometimes initially demonstrated by ileal backflow on enema examination and is therefore shown under both "small intestine" and "colon" in the table. There is no overlap of cases.

COLON

Major diverticular disease (diverticulosis, diverticulitis, diverticular disease) was the commonest finding (Table IV). Ulcera-

TABLE II-Lesions of Oesophagus, Stomach, and Pylorus/Duodenum

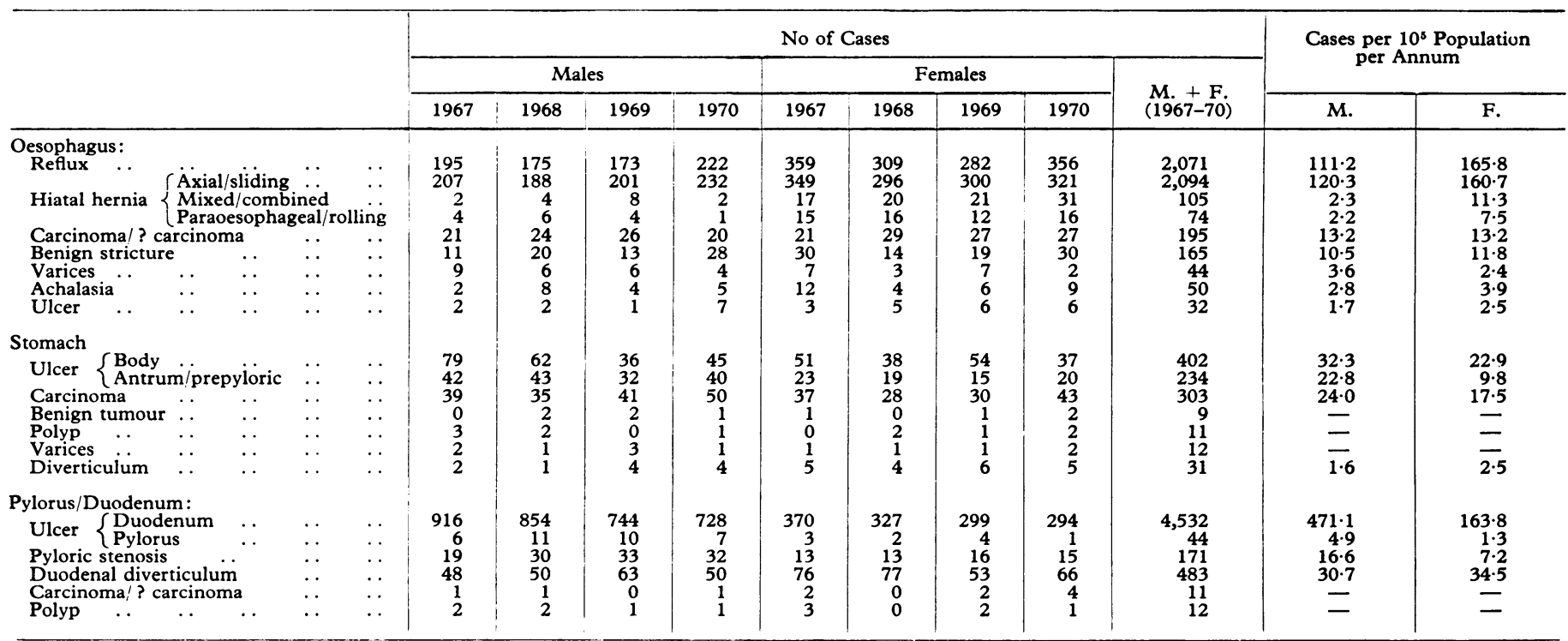

TABLE III-Comparative Estimated Annual Rates of Detection of Peptic Ulcer per $10^{5}$ Population at Risk

\begin{tabular}{|c|c|c|c|c|c|c|c|c|c|c|c|c|c|c|c|c|}
\hline \multirow{4}{*}{$\begin{array}{c}\text { Age } \\
\text { Groups }\end{array}$} & \multicolumn{7}{|c|}{ N.E. Scotland. Present study } & \multicolumn{2}{|c|}{ S.E. England. (Doll et al.* 1951) } & \multicolumn{7}{|c|}{ N. England (Pulvertaft + , 1959) } \\
\hline & \multicolumn{4}{|c|}{ Gastric Ulcer } & \multirow{2}{*}{\multicolumn{2}{|c|}{$\begin{array}{l}\text { Duodenal } \\
\text { Ulcer }\end{array}$}} & \multirow{3}{*}{$\begin{array}{l}\text { All Peptic } \\
\text { Ulcer. } \\
\text { Male Only }\end{array}$} & \multirow{3}{*}{$\begin{array}{c}\text { Age } \\
\text { Groups }\end{array}$} & \multirow{3}{*}{$\begin{array}{l}\text { All Peptic } \\
\text { Ulcer. } \\
\text { Male Only }\end{array}$} & \multirow{3}{*}{$\begin{array}{l}\text { All Peptic } \\
\text { Ulcer. } \\
\text { Male Only }\end{array}$} & \multicolumn{4}{|c|}{ Gastric Ulcer } & \multirow{2}{*}{\multicolumn{2}{|c|}{$\begin{array}{l}\text { Duodenal } \\
\text { Ulcer }\end{array}$}} \\
\hline & \multicolumn{2}{|c|}{ Body } & \multicolumn{2}{|c|}{ Antrum } & & & & & & & \multicolumn{2}{|c|}{ Body } & \multicolumn{2}{|c|}{ Antrum $\ddagger$} & & \\
\hline & M. & $\mathrm{F}$. & M. & F. & M. & $\mathrm{F}$. & & & & & M. & F. & M. & F. & M. & F. \\
\hline $12-19$ & 0 & 7 & 1 & 0 & 54 & 13 & 55 & & & & , & . & & & & \\
\hline $20-29$ & 17 & 3 & 10 & 3 & 389 & 64 & 416 & & & & 3 & 0 & & & 93 & 17 \\
\hline $30-39$ & 22 & 27 & 20 & 4 & 556 & 167 & 598 & $25-$ & 276 & - & 22 & 10 & & & 197 & 44 \\
\hline $40-49$ & 67 & 37 & 40 & 13 & 631 & 262 & 738 & $35-$ & 328 & - & 36 & 22 & & & 202 & 83 \\
\hline $50-59$ & 73 & 55 & 35 & 10 & 626 & 249 & 734 & $45-$ & 307 & - & 84 & 41 & & & 321 & 103 \\
\hline $60-69$ & 117 & 59 & 54 & 23 & $\begin{array}{l}020 \\
840\end{array}$ & $\begin{array}{l}249 \\
236\end{array}$ & 1,011 & $55-$ & 345 & - & 106 & 52 & & & 369 & 68 \\
\hline $70-79$ & 97 & 67 & 57 & 24 & 590 & 263 & 744 & $65-$ & 168 & - & 48 & 49 & & & 275 & 63 \\
\hline $80+$ & 22 & 136 & 55 & 24 & 494 & 190 & 571 & & & & & & & & & \\
\hline All ages & 32 & 23 & 22 & 10 & 477 & 165 & 531 & All ages & 207 & 293 & 47 & 28 & 11 & 3.5 & 235 & 63 \\
\hline
\end{tabular}

*Annual risk of developing an ulcer.

†Age at time of diagnosis.
$\ddagger$ Calculated from data of Pulvertaft (1959).

TABLE IV-Selection of Abnormal Findings in Intestines

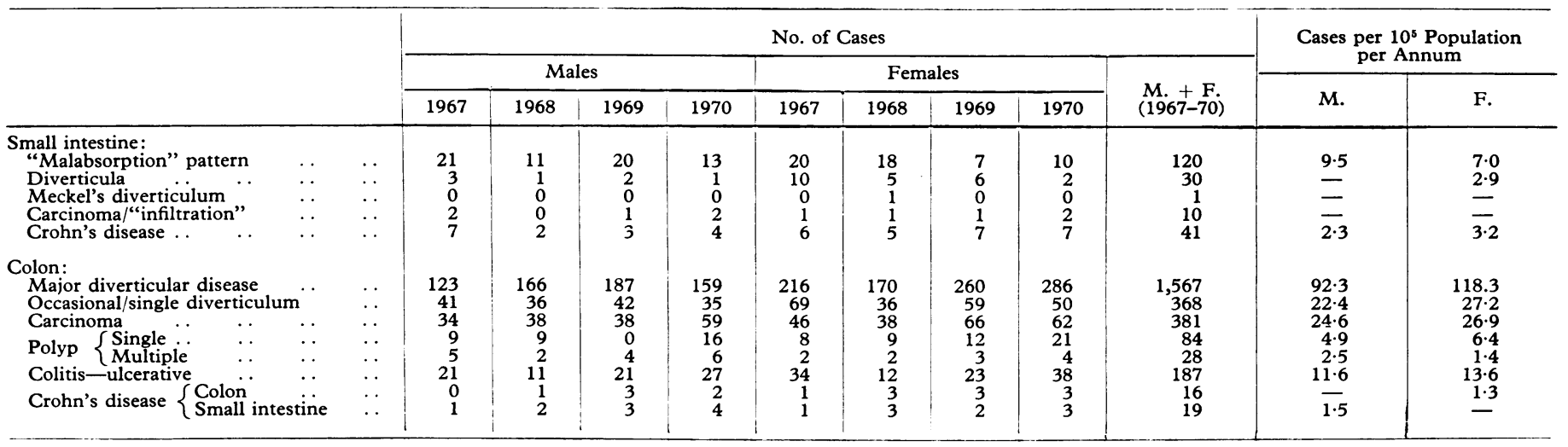


tive colitis was diagnosed firmly more often than Crohn's disease of the colon. The diagnosis by radiology of carcinoma and of major diverticular disease increased slightly over the four-year period.

\section{DISCUSSION}

Study of the frequency of occurrence of lesions of the alimentary tract is frustrated because there is no simple method of population screening such as mass miniature radiography of the chest, and not all alimentary lesions produce symptoms. It is very difficult to make a valid assessment of the occurrence of asymptomatic lesions in a community. It is possible, with small numbers, to carry out special surveys on asymptomatic volunteers, such as on the occurrence of diverticular disease (Manousos, Truelove, and Lumsden, 1967). Such studies, however, are not feasible with really large samples and for all lesions. Necropsy series will ordinarily be highly selective; however, Watkinson (1960), from a more representative massive necropsy survey, obtained much valuable information, but this was limited to one type of lesion-peptic ulcer. The present radiological survey was not designed primarily to identify asymptomatic lesions, yet, because of the high annual rate of examinations of the population at risk, many incidental lesions have been detected and are included in the tables. The incidence of asymptomatic lesions must be known in order to derive data for total incidence, and this information is complementary to and does not deny the importance, in its own right, of incidence of the symptomatic lesions that ordinarily bring the patient to the doctor.

In general, lesions cannot be identified and recorded unless they lead to medical consultation, full examination, and retrievable documentation. Most survey methods of alimentary tract disease suffer from these limitations, and the present study is no exception. Deficiencies and inaccuracies in recording even symptomatic lesions must also occur in this survey because of previous operation or death, or other reasons for failure of referral for contrast radiology. Nevertheless, modern attitudes in both patients and doctors ensure that few patients will escape adequate investigation if they have persistent symptoms. This is confirmed by the high proportion of the population examined each year ( 1 person in 50, or 1 person in 12.5 examined at least once in the four-year period) and also by the high rate of normal examinations (Table I).

Some advantages of this regional survey are that the area is bounded by sea to the east, by mountains to the west, and the southern and northern borders of the region contain only a very small part of the population. In the overlap area the probability of a patient being referred north or south is evenly distributed and could have but little effect on overall calculations. The examinations are carried out by a unified department carrying a graduate school of radiology and serving the entire population-part town, part rural, part industrial-of the defined geographical area. Thus the survey method is representative and economical, being based on data generated from routine departmental work. It allows analysis of age at diagnosis, of sex, and of coincidence among recorded lesions. As each diagnosis is entered only in the year that it is first made, and as the annual yield for most lesions is rather constant (Tables II-IV), it follows that the number of new lesions diagnosed by radiology each year must be related to the annual incidence, though the validity and accuracy of these estimates must vary between lesions.

Good estimates of the incidence of some more severely symptomatic or rapidly fatal lesions, such as carcinoma of the oesophagus, may be obtained from malignant disease registers and this survey agrees with locally available data (J. F. Philip, personal communication, 1971). But in conditions with less morbidity there is much more difficulty, in lesions such as peptic ulcer or hiatal hernia, in avoiding the addition of cases that presumably could have been detected earlier. The difference between incidence and prevalence then becomes blurred.

Other methods of estimating symptomatic disease also have disadvantages which are familiar to clinicians interested in gastrointestinal disease. Hospital record systems, where incidental diagnoses without immediate clinical significance are commonly omitted, include only inpatients. Necropsy series, unless specially arranged to study a particular type of lesion (Watkinson, 1960) cannot be representative, and moreover are difficult to relate to symptomatic disease. Other radiological surveys have been carried out but these have not been related to a defined population: Dempster $(1957,1958)$ enumerated lesions detected; other series dealt with individual lesions in selected groups of patients (Pemberton, Black, and Maino, 1947; Grout, 1949; Welch, Allen, and Donaldson, 1953; Ramson, 1954; Conway-Hughes, 1956; Vandervelde and Carlson, 1964). We have been unable to find information related to a defined population and therefore comparable with the present survey.

Specially mounted surveys limited to the one type of lesion have been carried out on peptic ulcer for males in South-east England by Doll et al. (1951) and for both sexes in Northern England (Yorkshire) by Pulvertaft (1959). The different survey figures are very difficult to compare and, moreover, relate to different periods (Table III). Nevertheless the age structure of the groups at the time of diagnosis agrees with the data from the other series. The findings of the present survey confirm that duodenal ulcer is much commoner in the north. This trend is also evident for antral gastric ulcer but is reversed for ulcer of the body of the stomach, which seems to be less common than in the south.

In some lesions with even less constant morbidity, such as hiatal hernia, there are even greater difficulties in radiological interpretation. Nevertheless, the remarkable similarity in the numbers of these lesions detected each year again does not suggest a very low or haphazard detection rate; indeed it is striking that the numbers of most lesions identified by radiology are similar from year to year.

The validity and accuracy of the estimates of incidence based on annual rates of detection by contrast radiology must obviously vary from lesion to lesion, but in general the estimate should progressively improve with increasing length of the survey period in this defined, fairly static, community.

The survey establishes an annual index of patients to serve as a starting point for detailed studies, which are in progress, of the natural history and other aspects of specific lesions.

The data also provide a measure of the work load on a radiology service for a given population. This is useful in planning radiological facilities for new departments.

We wish to thank Professor R. D. Weir, Department of Public Health and Social Medicine, for his advice and Mrs. M. C. Smith for secretarial help.

\section{References}

Conway-Hughes, J. H. L. (1956). British fournal of Radiology, 29, 331.
Dempster, W. H. (1957). British fournal of Radiology, 30, 31.

Dempster, W. H. (1957). British fournal of Radiology, 30, 31.

Doll, R., Jones, F. A., and Buckatzsch, M. M. (1951). Medical Research Council, Special Report Series, No. 276.
.

Grout, J. L. A. (1949). British fournal of Radiology, 22, 442

Manousos, O. N., Truelove, S. C., and Lumsden, K. (1967). British Medical Ұournal, 3, 762

Pemberton, J. D. J., Black, B. M., and Maino, C. R. (1947). Surgery, Gynecology and Obstetrics With International Abstracts of Surgery, 85, 523.

Pulvertaft, C. N. (1959). British fournal of Preventive and Social Medicine, 13,131 .

Ramson, H. N. (1954). Gastroenterology, 26, 12 . Roentgenology, Radium Therapy, and Nuclear Medicine, 92, 989.

Watkinson, G. (1960). Gut, 1, 14 .

Welch, C. E., Allen, A. W., and Donaldson, G. A. (1953). Annals of Surgery, 138,332 . 